\title{
Lepadarq

\section{ESPACIOS OFICIALES Y DE RESISTENCIA: TRAMAS DE SIGNIFICACIÓN EN LOS CANDOMBES CONTEMPORÁNEOS EN MONTEVIDEO}

OFFICIAL AND RESISTANCE SPACES: WEBS OF SIGNIFICANCE IN CONTEMPORARY CANDOMBES IN MONTEVIDEO 


\title{
Espacios oficiales y de resistencia: tramas de significación en los candombes contemporáneos en Montevideo
}

\author{
Alejandro Gortázar ${ }^{a}$
}

Resumen: El artículo se propone, mediante una revisión de la bibliografía y de los discursos de la comunidad afrodescendiente montevideana, delimitar teóricamente el problema del candombe como configuración cultural, trazar algunos problemas históricos y sus distintas posiciones en la cultura nacional contemporánea, en especial en la segunda mitad del siglo $\mathrm{XX}$ hasta la actualidad. En ese sentido los candombes se definen como prácticas artísticas de la comunidad afrodescendiente, que implican una sociabilidad y una serie de espacios de legitimación, y también un lenguaje común de negociación con la sociedad envolvente. En este marco conceptual me interesa explorar dos espacios de oficialización de los candombes por parte del Estado: los vinculados al carnaval montevideano y la patrimonialización de determinados "toques madres", asociados a los barrios Sur, Palermo y Cordón Norte, en conjunto con organismos internacionales como la UNESCO. Surge también de este análisis preliminar las respuestas de la sociedad civil organizada para seguir dotando de significación a espacios públicos propios, lugares de memoria colectiva, e incluso disputar espacios a la especulación inmobiliaria. En las últimas décadas los candombes han experimentado un proceso de expansión fuera de su base territorial histórica, erigiéndose en una de las representaciones privilegiadas de "lo nacional". Ese desplazamiento tiene múltiples impactos en la cultura del tambor, en sus practicantes y en la sociedad hegemónica, que requerirán una mayor profundización en investigaciones futuras.

\section{Palabras Clave:}

Afrodescendientes, Candombe, Racismo, Carnaval, Hegemonía.
Abstract: The article proposes, through a review of the bibliography and the discourses of the Afro-descendant community of Montevideo, to theoretically delimit the problem of candombe as a cultural configuration, to trace some historical problems and their different positions in contemporary national culture, especially in the second half of the 20th century to the present day. In this sense, candombes are defined as artistic practices of the Afro-descendant community, which imply sociability and a series of legitimation spaces, and also a common language of negotiation with the surrounding society. In this conceptual framework, I am interested in exploring two spaces for the officialization of candombes by the State: those linked to the Montevideo carnival and the patrimonialization of certain "toques madres", associated with the Sur, Palermo and Cordón Norte neighborhoods, in conjunction with international organizations like UNESCO. It also emerges from this preliminary analysis the responses of organized civil society to continue giving meaning to their own public spaces, places of collective memory, and even contesting spaces for real estate speculation. In recent decades candombes have undergone a process of expansion outside their historical territorial base, establishing themselves as one of the privileged representations of "the national". This displacement has multiple impacts on the culture of the drum, on its practitioners and on the hegemonic society, which will require further study in future research.

Keywords:

Afrodescendants, Candombe, Racism, Carnival, Hegemony.

\footnotetext{
${ }^{\text {a }}$ Universidad de la República, Uruguay. Doctor en Letras por la Universidad Nacional de La Plata (Argentina). Esta investigación se desarrolla en el marco del proyecto "La cultura popular como desafío a los estudios latinoamericanos: usos y prácticas culturales de las clases subalternas", coordinado por Gustavo Remedi y financiado por el Fondo Clemente Estable de la Agencia Nacional de Investigación e Innovación (ANII) de Uruguay.
} 


\section{INTRODUCCIÓN}

En un diálogo al comienzo de la obra El desalojo en la calle de los negros de Jorge Emilio Cardoso (1996) Fausto le dice a Doña Coca: "Vení, Coca. Vení y mirá esta calle. Gran parte del alma de este pueblo se formó en ella y hoy nadie lo toma en cuento. Seguro, que estos bárbaros nos echan mañana y tiran todo abajo" (1996: p. 41). La obra de Cardoso, como él mismo sostuvo, es el símbolo de un momento traumático para el colectivo afrodescendiente de Montevideo: los desalojos de los conventillos Mediomundo y Ansina en 1978 perpetrados por la dictadura cívico-militar (19731985). ${ }^{1}$ La cita ilustra cómo los y las afrodescendientes practican y viven la ciudad, y en especial el barrio. La reflexión de Fausto remite a la calle, a lo que la calle significa, y en ese sentido un poco antes los personajes recuerdan al músico Pedro Ferreira y a las comparsas Libertadores de África y Fantasía Negra. Es la memoria del carnaval montevideano de los años cincuenta, momento de la oficialización del desfile de Llamadas por parte de la Intendencia Municipal de Montevideo en el Carnaval de 1956, un momento clave en la formación del "alma del pueblo", como dice Fausto. En la obra de Cardoso, la lucha por la vivienda es al mismo tiempo una lucha por el territorio de los candombes y su memoria. ${ }^{2}$

Pensados como configuración cultural ${ }^{3}$, los candombes son una expresión artística de los sectores populares, con una gama diversa de recursos y prácticas (desde la canción hasta la comparsa), con sus espacios de legitimación y sus interacciones con diversos dispositivos estatales y de la sociedad civil a nivel local, nacional y global. Como tal es inseparable, al menos hasta la segunda mitad del siglo XX, de un espacio determinado de la ciudad de Montevideo: los barrios Sur, Palermo y Cordón Norte, barrios que rodean el casco colonial histórico de Montevideo (hoy llamados Ciudad Vieja y Centro). Por esa razón es imprescindible analizar históricamente los candombes en relación al desarrollo de la ciudad y a las distintas formas de practicarla. La relación se vuelve particularmente tensa en la segunda mitad del siglo XX, cuando los distintos gobiernos y agentes inmobiliarios comienzan el proceso de demolición de casas de inquilinato y conventillos, formas de la vivienda popular que se consolidaron a fines del siglo XIX, y que son, además de las calles, los espacios privilegiados del candombe y sus ejecutantes. Los y las afrodescendientes fueron los principales "clientes" de estas formas de vivienda precarias, en unos terrenos cercanos al centro

\footnotetext{
${ }^{1}$ El autor dijo "quise dejar un símbolo de unidad, de agruparnos para resistir, de afirmarse en el derecho y en la igualdad", refiriéndose a su obra en el marco de un seminario sobre literatura escrita por afrodescendientes en Uruguay que impartí durante el segundo semestre de 2017.

2 Tomo la expresión "los candombes", como forma de englobar distintas expresiones artísticas, de la obra del musicólogo Coriún Aharonián (2010).

3 El antropólogo Alejandro Grimson define una configuración cultural como "un marco compartido por actores enfrentados o distintos", que ayuda a articular "la heterogeneidad social". Son por lo tanto campos de posibilidad dado que en cualquier espacio social hay representaciones, prácticas e instituciones posibles, imposibles y hegemónicas; conforman una totalidad de partes diferentes que con una específica lógica de interrelación; comparten una "trama simbólica común, lenguajes verbales, sonoros y visuales en los cuales quienes disputan pueden a la vez entenderse y enfrentarse"; y finalmente, en una configuración deber haber un sentido de "lo compartido", sea lo mayoritario, las creencias o prácticas de los sectores populares o como propuestas de las élites (GRIMSON, 2011, p. 172-177).
} 
histórico de la ciudad, es decir, próximos a los lugares de trabajo o al transporte necesario para llegar a él.

Lo que el personaje de la obra de Cardoso rememora, y lo que llamamos "candombe" hoy, incluye distintas expresiones artísticas y culturales como el candombe-canción, los "toques madre" (de Barrio Sur, Palermo y Cordón Norte) como se les denomina desde su patrimonialización, la comparsa barrial, el desfile oficial de Llamadas y la competencia en el Teatro de Verano durante el carnaval. Investigar los candombes implica considerar esta heterogenidad de productos culturales y contextos. Con frecuencia se asume que es posible tender una línea de continuidad, una "tradición", que uniría los candombes contemporáneos con los "bailes de negros" de la colonia, registrados por los viajeros y otros funcionarios coloniales. Esa continuidad deberá tener en cuenta al menos tres bloques bien diferenciados: el de los "candombes históricos" que va de la Colonia a finales del siglo $\mathrm{XIX}$, período en el que se configuran distintas formas de organización de las personas esclavizadas: cofradías, salas de nación, sociedades y comparsas; otro que va de 1905 a 1956, cuando el candombe ingresa al carnaval montevideano y posteriormente es nacionalizado; $y$, de 1956 hasta hoy, un tercer momento de oficialización en el carnaval montevideano y su mayor mercantilización, así como su patrimonialización. En los tres momentos de los candombes, que no constituyen una cadena lineal y teleológica, sino procesos de transculturación en el que se pierden y seleccionan distintos elementos (instrumentos musicales, danzas, coreografías, vestimentas, personajes, entre otros), la población afrodescendiente encontró distintas formas de apropiación del espacio público, así como formas de asociación colectiva y de negociación con el Estado y con la cultura dominante.

La continuidad de los candombes, como señala Aharonián, viene dada por el grupo humano que los practica (AHARONIÁN, 2010, p. 146). En todas las épocas históricas, en todas sus variantes, los candombes significaron la construcción de una esfera pública propia, ¿plebeya?, un espacio de sociabilidad y de construcción de liderazgos y estéticas asociadas a artistas y linajes de artistas (FERREIRA, 2008, p. 97). El desplazamiento de la población afrodescendiente fuera de los barrios históricos durante la dictadura cívico-militar constituyó un ataque directo a las posibilidades de reproducción y crecimiento de los candombes. Sin embargo, en las últimas décadas la música de los tambores de candombe se volvió una característica de la ciudad en toda su extensión, con comparsas de candombe en casi todos los barrios y con Desfile de llamadas masivo y televisado; y se expandió a nivel nacional con músicos populares blancos que lo incorporaron a sus repertorios como Jaime Ross, Los Olimareños o José Carbajal (El Sabalero) y con la creación de comparsas en distintas ciudades del mundo donde hay migrantes uruguayos.

En los últimos diez años el Estado uruguayo profundiza en una perspectiva de derechos humanos, y en particular de los derechos culturales, que atraviesa muchas de sus acciones, y se expresa en la promulgación de leyes y en la creación de distintas políticas, programas y acciones. En abril de 2007 Uruguay ratifica por ley las Convenciones de Patrimonio Inmaterial (2003) y de Diversidad Cultural (2005) de la UNESCO. Ambos mecanismos fueron importantes para el reconocimiento de la cultura afro-uruguaya por parte del Estado. En 2006 se promulga la ley 18.059 que establece el 3 de 
diciembre, que toma precisamente la fecha de la llamada de despedida de Medio Mundo en 1978, como Día nacional del candombe, la cultura afrouruguaya y la equidad racial. Al año siguiente se dedica el Día del Patrimonio a los afrodescendientes y a dos de sus vedettes (Marta Gularte y Rosa Luna) y la cantante Lágrima Ríos, quien falleció ese año. En octubre de 2009 el candombe entra en la "Lista representativa del Patrimonio Cultural Inmaterial de la Humanidad" de la UNESCO, aprobada por la Comisión Intergubernamental. El Ministerio de Educación y Cultura creó el Grupo Asesor de Candombe, integrado por la sociedad civil, y desarrolló un Plan de Salvaguarda del candombe y su espacio sociocultural, presentado en 2015. A estas medidas de reconocimiento de la diversidad cultural se suman otras acciones afirmativas como la creación de cuotas para acceder al trabajo previstas e instrumentadas con la Ley $N^{\circ} 19.122$ de 2013, reglamentada al año siguiente, y que también incluye, en el campo de la educación, la incorporación del "legado de las comunidades afrodescendientes" en los programas educativos y de formación docente, así como la promoción de la investigación nacional (Art. 8).

Por estas razones es imprescindible analizar los candombes en el marco de las múltiples presiones que se ejercen sobre sus formas: el negocio de la producción del espacio y la urbanización promovido por el capital (HARVEY, 2013), la industria del carnaval y de la música, el Estado, sus políticas sociales y culturales, y sus relaciones con la cooperación internacional. Y también de las resistencias de distintos colectivos que, desde la posdictadura hasta hoy, pugnan por construir sentidos alternativos del territorio, por procurar que ese espacio, que está transformándose rápidamente y los expulsa, no pierda su carga simbólica, como espacio social en el que los y las afrodescendientes construyeron históricamente los candombes.

\section{El espacio oficial de las comparsas}

Si bien las primeras comparsas ya pueden ubicarse hacia 1832 (AYESTARÁN, 1953, p. 71), la categoría de "comparsa de lubolos" se incorporó oficialmente al carnaval montevideano en 1905 (OLIVERA, 2009, p. 186). A fines del siglo XIX convivieron con las últimas expresiones de los candombes de las salas de nación, y en su repertorio se incluían variadas especies musicales como la habanera, el tango o el milongón (AHARONIÁN, 2010, p. 126 y MERINO, 1982, p. 73). Lo lubolos eran blancos que se pintaban de negro la cara, que llevaban buzos y medias negras, vestimenta que hacia 1980 todavía se usaba en las comparsas según Merino (1982, p. 73). En algún momento, indeterminado aún, el término definió a "todas las comparsas de negros" (MERINO, 1982, p. 74). Actualmente la categoría, dentro del carnaval montevideano, es "Sociedad de negros y lubolos".

La incorporación oficial de las comparas, con la denominación de "Desfile de Llamadas", se produjo en el verano de 1956. El año anterior la organización Asociación Cultural y Social Uruguay (creada en 1941, hoy ACSUN) inició negociaciones con la Comisión de Fiestas de la Intendencia, a través de uno de sus integrantes Oscar Larraura Suárez, un político afrodescendiente edil por el 
Partido Colorado (ALTAMIRANDA, 2004, p. 28-29). Este hecho representa un hito en la historia de la resignificación del candombe en la sociedad envolvente e implicó, otra vez, la reconfiguración del territorio del candombe en distintos sentidos.

Según Ruben Galloza, pintor, escritor y militante afro, la idea original de ACSU (actualmente ACSUN) no era incluirse en el carnaval montevideano:

(...) un festejo que se iniciaba el 25 de diciembre y terminaba el 6 de enero en el barrio Sur, con dos escenarios y premios a cada elemento destacado, y era una fiesta auténticamente folklórica, no carnavalesca. Era una fiesta fuera del Carnaval. Teníamos que hacer una semana de festejo. Pero nunca nos llevaron el apunte, decían que salía mucha plata (PORZECANSKI, 2006, p. 114)

El sentido de la acción era destacar las llamadas de los barrios tradicionales en su dimensión folclórica, apartándose del carnaval y cobrando una significación autónoma. Según Olivera y Varese, Justino Zavala Muniz, escritor y en ese momento jerarca municipal, tenía la idea de separar los espectáculos folklóricos o nativistas del carnaval. Según los autores por los años cuarenta algunos conjuntos folkóricos participaban en los tablados del carnaval y Zavala entendía que eso "podía llegar a desnaturalizar las tradiciones camperas". De hecho logró separarlas, no así con las llamadas de Candombe (OLIVERA, 2009: 151).

El resultado de la negociación entre sociedad civil y el gobierno municipal no fue el esperado, pero al mismo tiempo Galloza señala que participa "en discrepancia", cuestionando algunos aspectos:

Pero finalmente, la pusieron en el Carnaval, que es la cosa que yo no estoy de acuerdo, a pesar de que he sido jurado un par de años, pero siempre estoy en discrepancia. La Llamada es una cosa popular e inorgánica. La Llamada no puede estar organizada, y menos la del Carnaval. La Llamada es una largada de tambor, una salida se encontraba con otra, era algo espontáneo. Lo que nosotros quisimos hacer era tomar todos esos elementos, la comparsa, y robustecerlos en, por ejemplo, una escuela de escoberos para que surjan, para que el escobero que sabe enseñe al otro (PORZECANSKI, 2006, p. 114115).

Las discrepancias con las llamadas oficiales, en el caso de Galloza, están centradas en la organización de la espontaneidad y en el valor folclórico de las comparsas, sus personajes tradicionales y su capacidad de reproducción dentro de la propia comunidad. Otras voces críticas 
apuntan a la mercantilización, como Olivera y Varese que afirman que fue "una medida genial para el turismo pero nefasta para el mantenimiento de las auténticas tradiciones afrouruguayas" (OLIVERA, 2009 , p. 140). Otros señalan además de las comparsas como empresas, el carácter competitivo y los fines poco transparentes de la competencia (AHARONIÁN, 2010, p. 124). Las palabras de Galloza, recogidas por Beatriz Santos y Teresa Porzecanski en una publicación de los años 90, resuenan en las críticas al espacio oficial del candombre realizadas por músicos y referentes afrodescendientes contemporáneos como Fernando “Lobo" Núñez Ocampo o “Chabela” Ramírez.

En una entrevista reciente realizada por Lucía Naser, la artista y militante Chabela Ramírez hizo referencia a la historia de este desacuerdo con la Comisión Municipal de Fiestas:

(...) en 1956 la comunidad nuestra estaba armando las "fiestas negras", que eran una semana con charlas, exposiciones... El candombe no era lo más importante. Incluía otras cosas, pero como había mucho desorden, ACSUN le pidió a la IM que interviniera y ayudara con la infraestructura, que el colectivo afro no tenía (y todavía no tiene, aunque avanzó en eso). El resultado fue que a toda aquella fiesta negra de una semana la IM la transformó en un día solo, el día de las Llamadas, en el que no se hace una fiesta de ida y vuelta, sino un desfile. Si lo mirás objetivamente, es como un desfile militar, una comparsa atrás de otra, cada diez minutos sale una. Antes las Llamadas tenían otra característica, porque eran siete comparsas las que salían, e incluso en determinado momento las de algunos barrios dejaron de venir: la gente de Colón, la del Cerro y otros lugares. Había comparsas que se quedaban en su barrio, porque no había apoyo ni siquiera de transporte para que vinieran. Después transformaron las Llamadas en un concurso, con ciertas características y reglas, y eso fue cambiando hasta hoy (NASER, 2017)

El relato que Galloza hacía en 1994 se repite con contundencia en la generación siguiente, Chabela Ramírez afirmaba en la entrevista que ella sacaría las comparsas del carnaval, porque la competencia no favorece el desarrollo del candombe y la "expresión popular". Y agrega: "Yo, por ejemplo, salgo en una comparsa porque mis hijos sacan una -Valores de Ansina- y porque una cosa que les enseñé a mis hijos es que para luchar hay que luchar por dentro". La frase expresa, de otra forma, aquel "estar en discrepancia", participar pero no dejar de hacer críticas y proponer alternativas, intentar torcer las llamadas y la participación de las comparsas en el concurso oficial. De hecho la comparsa Valores de Ansina, formada en 2014, se define como "heredera y responsable del tradicional toque de Ansina" del Barrio Palermo. En ese sentido la comparsa no solamente participa en la competición, sino que sale los domingos a las 17 horas desde las calles Magallanes y Gonzalo Ramírez, en el barrio Palermo, recuperando la práctica de la llamada espontánea o no institucionalizada (AHARONIÁN, 2010, p. 124). 
A partir de la oficialización de la comparsa en el Carnaval montevideano queda pautada una forma de actuación de las comparsas, y que se expresa en los reglamentos establecidos por la Intendencia en cada carnaval. Cada agrupación "es precedida por estandartes y banderas (y figuras corpóreas -estrellas, medialunas- llevadas como estandartes), y está constituida, además de los tamboriles, por varios personajes" (AHARONIÁN, 2010, p. 125). El número de tambores ha variado con el tiempo: Ayestarán afirmaba que eran 20 o 30 (1990: 11), pero en las sucesivas reglamentaciones el número ha subido a 40 como mínimo, con comparsas que han incorporado más de 100 (AHARONIÁN, 2010, p. 124). Los personajes se pueden distinguir claramente entre los tres tradicionales (la mama vieja, el gramillero y el escobero o escobillero) y los otros que vienen de fuera como la vedette y el travesti (AHARONIÁN, 2010, p. 125).

El Desfile oficial de Llamadas, como sostiene el historiador Reid Andrews, es parte de un proceso de nacionalización de distintas expresiones de la música popular que se dio en América Latina entre 1930 y 1950. Un desplazamiento de la cultura hegemónica para captar a los sectores populares que se dio en países como Cuba, Brasil o Guatemala (ANDREWS, 2011, p. 157). Siguiendo la idea de alteridades históricas de Rita Segato, el Desfile Oficial de Llamadas se convirtió, con el paso del tiempo, en una forma hegemónica de construir alteridad, que modeló cuerpos e identidades de los y las afrodescendientes de, al menos, los barrios Sur, Palermo, Reus al Sur y Cordón Norte, así como las representaciones que la mayoría blanca se hizo del colectivo.

Este evento se convirtió en poco años en un espacio de expresión cultural y una actividad económica que fue involucrando, progresivamente, distintos oficios y trabajadores: directores, compositores, coreógrafos, escoberos, mamas viejas, vedettes, cuerpo de baile, cantantes, diseñadores de vestuario y músicos (ANDREWS, 2011, p. 161). Es frecuente en los debates y disputas públicos que se producen en cada carnaval que aparezca la dimensión económica de la actividad, aunque rara vez en su globalidad. En una nota publicada por El Observador en 2017 a raíz de una propuesta de AUDECA (Asociación Uruguaya de Candombe), la organización que reúne a la mayoría de las comparsas, para renegociar el pago por derechos de imagen con la empresa que televisa el evento, el periodista Juan Samuelle informaba que los gastos de una comparsa para desfilar rondaban los 600 mil pesos. Según AUDECA el dinero de los premios, los derechos de imagen (32 mil pesos) y la publicidad, muchas veces no alcanza para cubrir los gastos (SAMUELLE, 2017). No son datos suficientes como para poder dimensionar la economía del Desfile, que debería incluir a la comparsa, pero también el aporte municipal, la venta de entradas y otras variables. Pero es un tema importante para poder hablar de cuánto de lo que se genera en las Llamadas impacta en la propia población afrodescendiente.

La oficialización del carnaval dio lugar a nuevas organizaciones civiles que se encargan del carnaval en acuerdo con la Intendencia de Montevideo. En el caso del candombe primero participan los Directores de las comparsas en la organización Directores Asociados de Espectáculos Carnavalescos Populares del Uruguay (DAECPU) creada en 1952. En el siglo XXI se crea la Asociación Uruguaya de Candombe (AUDECA), de 2004, que actualmente nuclea a más de 40 comparsas. La 
organización histórica, de los dueños de las agrupaciones, es la que gestiona el concurso oficial anual en el Teatro de Verano "Ramón Collazo" y parte de los escenarios. En el desfile oficial de Llamadas compiten unas 46 comparsas, ese número se repite desde 2018 , mientras en el concurso oficial participan por lo general 6, siendo 8 el máximo posible. Las comparsas que compiten en ciertas oportunidades abandonan la prueba de admisión y se concentran en el Desfile de Llamadas, porque no pueden afrontar los gastos necesarios para hacer un espectáculo en el Teatro de Verano, es el caso de la histórica C 1080 (su nombre hace referencia a la dirección del Conventillo en la calle Cuareim 1080) que no se presentó en el carnaval de 2020, o Valores de Ansina que no lo hizo en 2018.

El Desfile de Llamadas oficial es otra forma de apropiación del espacio público, que implica una ocupación del lugar de memoria del candombe (los Barrios Sur y Palermo) desde arriba. Este desde arriba es lo que determina que haya "una estructura fija, reglamentada" (AHARONIÁN, 2010, p. 124). El mapa del Desfile del año 2019 lo muestra con claridad:

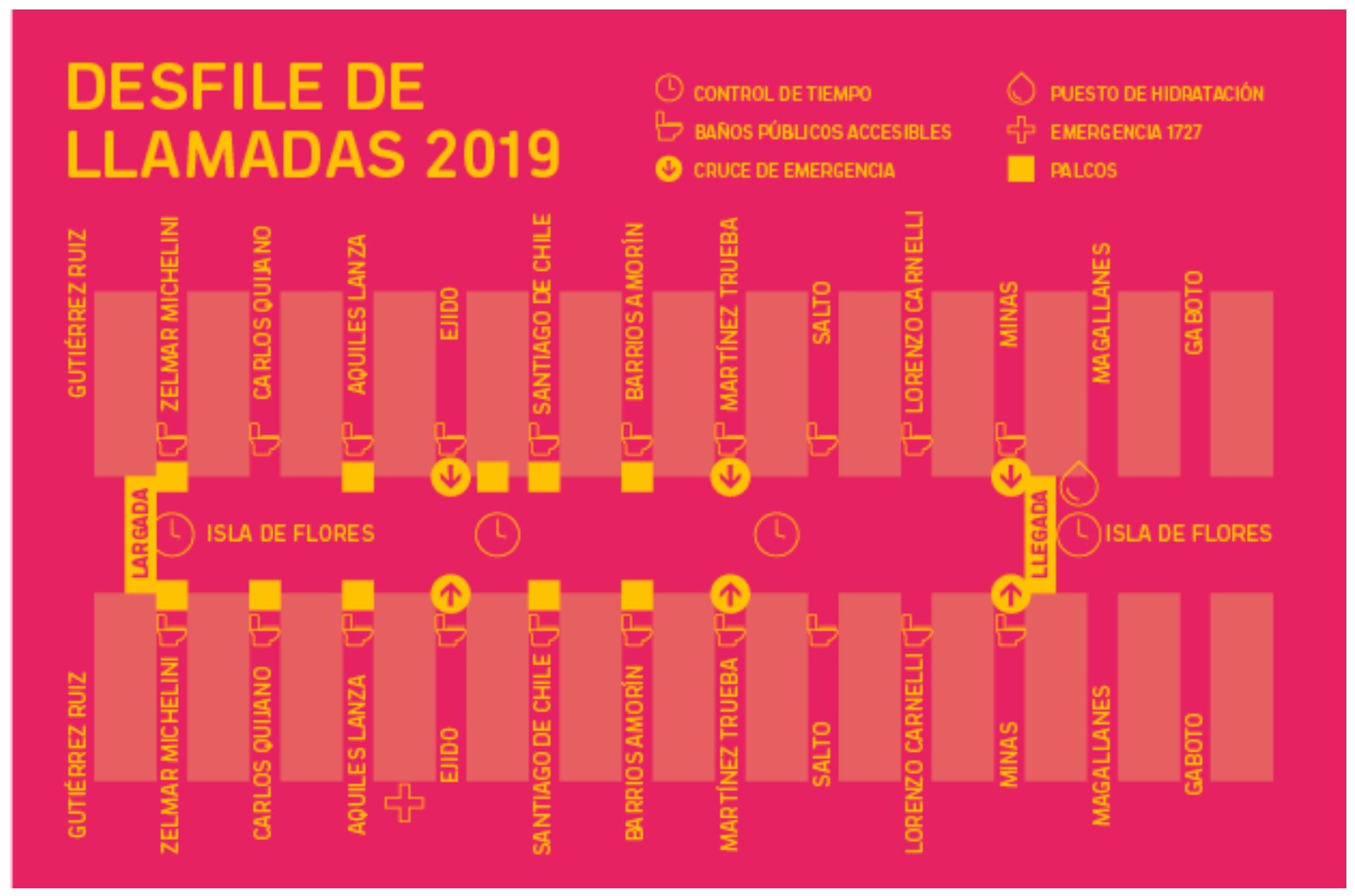

Figura 1. Plano del Desfile de Llamadas 2019 publicado por la Intendencia de Montevideo

El desfile se extiende por diez cuadras (1 kilómetro) por una sola calle, Isla de Flores, desde Gutiérrez Ruiz hasta Minas (desde el Barrio Sur hacia Palermo), con cuatro controles de tiempo, palcos para las autoridades y para los turistas, puestos de hidratación, baños públicos y cruces para disponer de salidas en caso de emergencia. Originalmente el desfile duraba un día, pero en la actualidad, dada la cantidad de comparsas (más de 50, entre las que compiten y las invitadas), se realiza en dos días consecutivos (que pueden ser tres por cuestiones climáticas en general jueves, 
viernes y sábado).

Esta disposición del espacio cambió históricamente, como puede apreciarse en el texto de Tomás Olivera Chirimini sobre el desfile de 1956:

(...) No se trataba tan solo de una competencia entre comparsas, sino que además se premiaban los mejores balcones y las puertas mejor adornadas. Conservo muchísimos detalles de aquella irrepetible fiesta popular y familiar. El balcón de mi familia materna, Minas 1033, fue uno de los premiados. EI recorrido del desfile configuraba un circuito que partía de las calles Cuareim (hoy Zelmar Michellini) e Isla de Flores (hoy Carlos Gardel), tomaba por Cuareim, Durazno, Minas, San Salvador, Ansina e Isla de Flores hasta el punto de partida (OLIVERA, 2009, p. 26).

Hay una diferencia de recorrido muy importante. Tal como lo describe es un recorrido circular, de casi 2 kilómetros y medio. Adicionalmente, las llamadas espontáneas hacían un recorrido, bastante definido también, entre los tres conventillos más importantes de cada barrio Cuareim (Barrio Sur), Ansina (Palermo) y Gaboto (Cordón Norte). Según Merino (1982, p. 18) la recorrida podía empezar desde cualquiera de los puntos de la ciudad. Además de la diferencia del recorrido, es interesante observar que el primer desfile oficial era una apropiación del espacio público que implicaba la participación de los vecinos con el embellecimiento de sus casas, era por lo tanto una forma de habitar el espacio barrial. En la memoria de Olivera "Ios tamborileros y los bailarines, como embrujados por sus ancestros, desfilaban apretujados entre el público que desbordaba las aceras" (2009, p. 27). Con el paso de los años, ese espacio fue ordenado cada vez más, controlando los desbordes, poniendo vallas, vigilando la participación de la población, incorporando actores como la televisión, regulando algunas actividades económicas, organizando espacios privilegiados como los palcos. Más allá de la regulación existen otras prácticas "informales" como el alquiler de balcones, la venta de artículos (máscaras, luces, entre otros), bebidas y alimentos. El Desfile oficial de Llamadas, y la economía que moviliza, necesita de un tratamiento especial en el marco de la apropiación de la "industria cultural" del Carnaval montevideano.

\section{Los candombes hoy: resistencia y espacios oficiales}

Las transformaciones de la ciudad que empiezan a darse en los años 40 y se recrudecen durante la dictadura cívico militar (1973-1985), empujaron a la población afrodescendiente a distintos puntos de la ciudad, como puede apreciarse en el análisis del Censo Nacional de 2011. Para Cabella, Nathan y Tenenbaum, la mayor concentración está en los barrios periféricos, alcanzando 
porcentajes altos entre los ubicados en el llamado "cinturón de pobreza", como Casavalle, Casabó, Punta de Rieles, La Paloma, Nuevo París y Pajas Blancas. Aún así entre un 5\% y un 13\% de la población afrodescendiente sigue viviendo en Barrio Sur y Palermo. Como sostiene Valentín Magnone, a partir del análisis de los autores, el mapa de la población con al menos una necesidad básica insatisfecha, coincide con los barrios en los que habitan los y las afrodescendientes en Montevideo. Las marcas de la racialización de las relaciones de clase, según expresión de Mario Margulis para Buenos Aires (MARGULIS, 1999, p. 37), siguen operando en el tejido urbano, y en los cuerpos y experiencias de la población afrodescendiente en Montevideo.

Las llamadas de despedida de la dictadura explicitaron la relación entre tamboriles y resistencia una vez llegada la democracia. Mientras se imponía el mito de la democracia, en parte difundiendo la posibilidad del regreso de los militares, algunos grupos de la sociedad civil lo pusieron en entre dicho. La institución Organizaciones Mundo Afro (OMA), creada entre 1985 y 1989, emergió con más fuerza en el espacio público en 1992 y a raíz de los contra-festejos de los 500 años de la conquista, tomando los tambores como herramienta política para denunciar la discriminación racial, y reclamar el lugar de los afrodescendientes en el relato nacional. Las acciones de desterritorialización "literal" de la dictadura (Argañaraz: 14) tuvieron su respuesta en distintos actores, y el candombe lo recogió no solamente a través de las llamadas espontáneas sino también en el candombe canción. En 1984 Jorginho Gularte, hijo de Martha Gularte, vedette y referente histórica del candombe, publica la canción "Tambor, Tambora” del disco La Tambora:

\author{
De que sirvió hacer llamadas \\ Que ingratitud \\ Cuanta cosa equivocada \\ (...) \\ Pues hoy quien pasa por Cuareim \\ ya no ve nada
}

La canción de Gularte funde la demolición del Conventillo de Cuareim de la dictadura cívico-militar con el debilitamiento de la cultura del tambor, e incluso marca el contrasentido que supone la celebración de las llamadas.

Sin embargo, al mismo tiempo que se advierte el peligro del "exterminio", y se apela a una conciencia de la historia reciente, se produce una reterritorialización de los candombes, como plantea Abril Trigo. Para el autor, los tambores cruzan la frontera entre artistas populares "respetables" (cultura legítima) y los artistas de carnaval, y también la que se mantenía entre la mezzomúsica y el folklore: "Esta interinfluencia revolucionaria se deshizo del antiguo concepto de «lo popular», y transformó dramáticamente tanto la canción popular como el carnaval. Mientras 
la primera ganó un nuevo mundo de posibilidades, el otro se volvió extremadamente sofisticado" (TRIGO, 1993, p. 723). El proceso de apropiación, en verdad mucho más largo como puede verse en los trabajos de Aharonián ya comentados, hizo que el candombe saliera de las fronteras de los barrios históricos (Sur y Palermo para Trigo) y se reterritorialice en toda la ciudad (TRIGO, 1993, p. 725). Afirma Milita Alfaro:

Luego de la catástrofe material y simbólica que significó la destrucción de los conventillos, el candombe ha demostrado una poderosa vitalidad que no solo le permitió sobrevivir al derrumbe sino que, en el marco de la dispersión urbana de la población negra, llevó los tambores a todos los rincones de Montevideo e, incluso, a muchos del interior del país (ALFARO, 2008, p. 92).

Cuarenta años después de los desalojos y las demoliciones los candombes forman parte del ambiente sonoro de Montevideo en casi todos los barrios, e incluso se incorporan al carnaval en los departamentos de Durazno (se realizan Ilamadas desde 1989), Cerro Largo y Colonia, que organizan llamadas de comparsas enteramente compuestas por blancos (OLIVERA, 2009, p. 140). También se realizan Ilamadas en Ciudad de la Costa en Canelones y otros departamentos.

Solamente en Montevideo, en un relevamiento no exhaustivo realizado para este trabajo da como resultado unas setenta comparsas distribuidas en casi todos los barrios. El mapa con las ubicaciones de los lugares de reunión de 44 comparsas muestra como el proceso, que originalmente se centraba en las afueras del caso histórico, se amplía en los barrios de la costa este de la ciudad (sobre todo en Buceo y Malvín) y fundamentalmente en los barrios periféricos al norte de Avenida Italia, es decir, en los barrios más pobres de la ciudad. Este fenómeno tiene su explicación en parte en el proceso de migración de la población de los barrios históricos a barrios periféricos, que se fue dando desde los años 50 del siglo XX, por razones ya expuestas.

Esta generalización del candombe fue desplazando el territorio de origen, pero también el papel de la comunidad afrodescendiente en su creación, transmisión y reproducción. A la par que este fenómeno crece, distintos actores confluyen en el instrumento del "patrimonio inmaterial" para salvaguardar el candombe. Con la creación del "Día del Candombe, la cultura afrouruguaya y la equidad racial” en 2006, el Estado uruguayo empezó un recorrido que incluyó la ratificación de las Convenciones de Patrimonio Inmaterial y Diversidad Cultural; y casi al mismo tiempo, la candidatura del candombe y el tango (en conjunto con Argentina) para entrar a la "Lista representativa del patrimonio inmaterial de la humanidad" de la UNESCO. La creación de un segundo espacio oficial, distinto al espacio de negociación del gobierno de la ciudad, implica una negociación con el Estadonación y su espacio dentro de la cooperación internacional. 


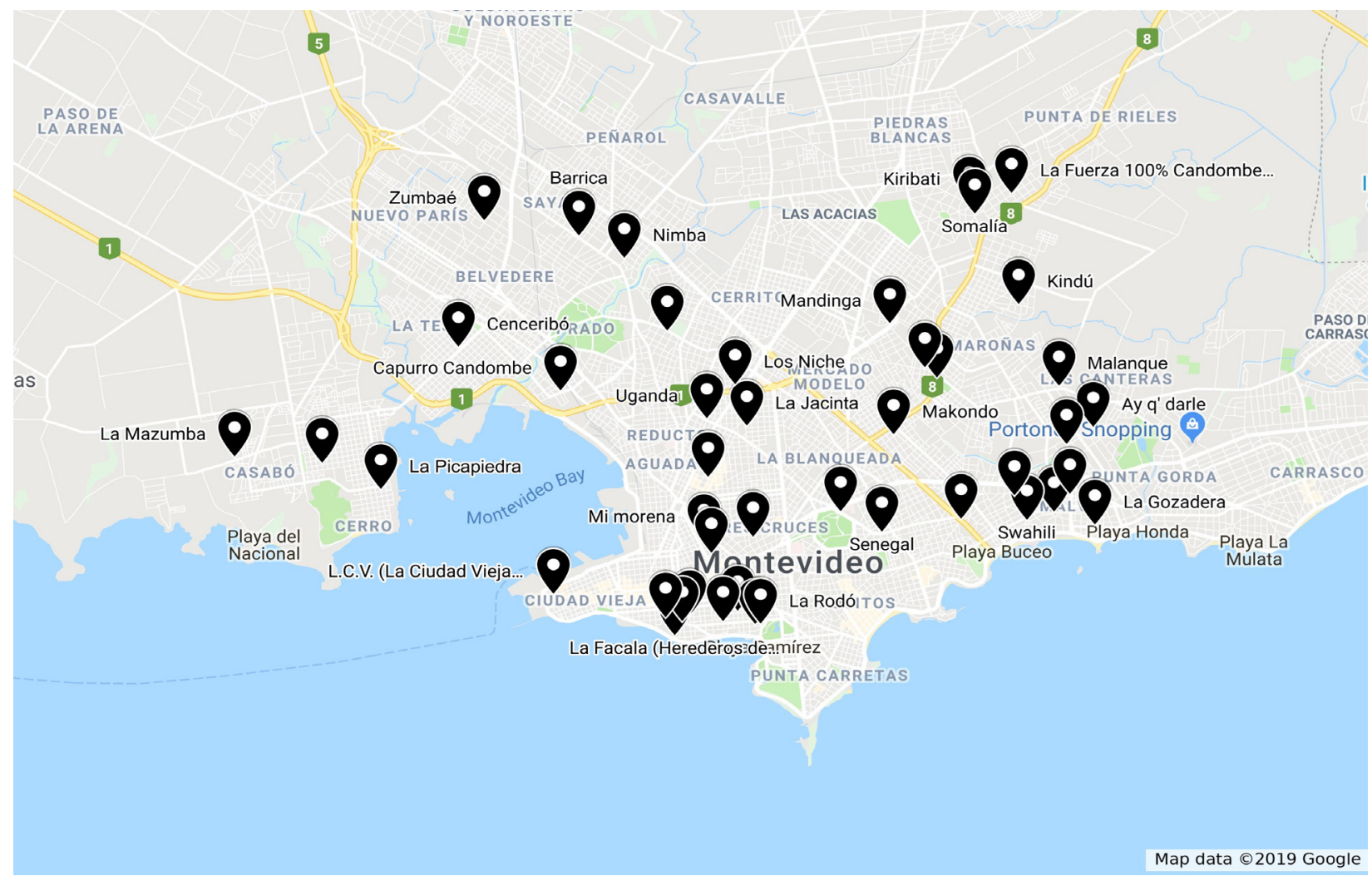

Figura 2. Ubicación de las comparsas en Montevideo elaborado con Google Maps

La candidatura presentada por la Comisión Nacional de UNESCO, se basó en la territorialidad, que se define como "espacio socio cultural", pero también en los colectivos humanos que desarrollan una "práctica comunitaria" o "ritual comunitario", y que son definidos así

Grupos de partícipes en eventos denominados "Llamadas de tambores" de Candombe, pertenecientes barrios de la ciudad de Montevideo; Sur, Palermo y Cordón Norte. Inumerables miembros de la comunidad fueron expulsados a otras zonas por segregación territorial. Algunos retornan en días especiales y eventualmete forman otras comparsas en zonas alejadas de ese núcleo histórico. Los miembros de estos grupos son descendientes de africanos esclavizados tempranamente afincados en estos territorios que fueron socio culturalmente marcados por esta presencia. Una característica relevante de estos grupos es la continuidad de líneas de descendencia familiar de ejecutantes respetados de tambores (UNESCO, 2009, p. 1. Traductor desconocido).

Es interesante el señalamiento del retorno de los antiguos habitantes a los barrios para incorporarse a este ritual comunitario, así como el rol de estas familias expulsadas durante 
la dictadura en la creación de comparsas en otros barrios. Un caso es el de la familia Pintos y su comparsa Zumbaé, que se define como "heredera de la tradición del barrio Cordón" (en su Fan Page de Facebook) pero su lugar de ensayo es el barrio Villa Teresa, unos 8 kilómetros al norte del centro histórico del candombe. La comparsa fue creada en 1978 y actuó hasta 1986, recién en 2005 vuelve al carnaval.

La candidatura y todas las acciones subsiguientes contribuyen a reterritorializar los candombes, anclándolos en los barrios tradicionales. Esta nueva oficialización está inscripta en un nuevo dispositivo de la UNESCO, en alianza con las redes locales de producción de conocimiento, el Estado y, fundamentalmente, los actores involucrados. La definición misma de Patrimonio Inmaterial centra su atención en los agentes sociales, desde la perspectiva de la recreación que hacen y de su función identitaria, "siempre y cuando se limiten a las prácticas no discriminatorias y conformes a la ética global emergente" (BORTOLOTTO, 2014, p. 6). En ese sentido el concepto de "salvaguarda" escapa a la idea de la protección que rige al "patrimonio material", se relaciona con una dimensión dinámica de la cultura, aunque sus herramientas (Lista nacional, Lista urgentes y Lista representativa) resulten sospechosas y objetivadoras (BORTOLOTTO, 2014, p. 8).

La candidatura uruguaya fue apoyada por una red local de producción de conocimiento sobre el candombe, saberes expertos que fueron citados en este trabajo de autores como Gustavo Goldman, Luis Ferreira y Coriún Aharonián, entre otros. Sobre este punto García Canclini señala que, en la entrada a la lista del patrimonio inmaterial

se consagran como superiores barrios, objetos y saberes generados por los grupos hegemónicos, porque estos grupos cuentan con la información y la formación necesarias para comprenderlos y apreciarlos, y por tanto para controlarlos mejor. Los historiadores, los arqueólogos y los políticos de la cultura definen cuáles son los bienes superiores que merecen ser conservados. Reproducen, así, los privilegios de quienes en cada época dispusieron de medios económicos e intelectuales, tiempo de trabajo y de ocio, para imprimir a esos bienes una mayor calidad (GARCÍA CANCLINI, 2010, p. 71).

El autor advierte sobre las articulaciones entre saber experto y grupos hegemónicos, que influye directamente en lo que se documenta y se conserva. La integración del Grupo Asesor de Candombe, creado en 2010 e incorporado por Resolución ministerial a la Comisión de Patrimonio de la Nación, consolidó a un conjunto de referentes del candombe en su integración representativos de los tres barrios: Fernando «Lobo» Núñez, Fernando Núñez Jr., Aquiles Pintos, Aníbal Pintos, Tomás Olivera Chirimini, Luis Ferreira, Isabel «Chabela» Ramírez, Waldemar «Cachila» Silva, Juan Gularte, José «Perico» Gularte, Benjamín «Chiquito» Arrascaeta y Beatriz Santos (RUIZ, 2015, p. 143). 
Es este Grupo Asesor el que instala la idea de los "toques madres" asociados a los barrios, y especialmente a los nombres de los Conventillos: Cuareim, Ansina y Gaboto. El concepto, como afirma Goldman, no estaba en la formulación original del expediente de UNESCO y "provee a los referentes y a las instituciones de salvaguardia de un concepto que reduce la complejidad histórica y musical de la práctica y permite definir fácilmente a quienes representan el candombe "auténtico»" (AMIGO, 2015, p. 52). La noción implica para Amigo una realidad social más que musical, y parece conformar "una especie de mitos fundacionales" que deben ser protegidos (2015, p. 52). Como señalan tanto Amigo como Bortolotto, el lenguaje del patrimonio intangible (identidad, tradición, transmisión) se integran al discurso del agente social, en un ida y vuelta permanente, y se utilizan pragmáticamente para vehiculizar las demandas hacia el Estado o la UNESCO (BORTOLOTTO, 2014, p. 4).

En ese sentido, los dos espacios oficiales (carnaval y patrimonio) se refuerzan, las comparsas del núcleo histórico (Sarabanda, Zumbaé, Sinfonía de Ansina, C 1080 y Conjunto Bantú, que no participó nunca en la competencia) recurren a los conceptos del patrimonio inmaterial en sus espectáculos de carnaval, en sus canciones y en su lenguaje cotidiano. Lo que se consolida es un grupo de actores claramente identificables que, como el expediente de la UNESCO, advierten una "amenaza" en la generalización del candombe en todo el territorio nacional. Y en tal sentido se puede interpretar también la organización de eventos como la "Llamada madre", financiada por el MEC y que muestra la preocupación por "generar eventos" y "generar recursos para el financiamiento de las comparsas a las que se encuentran vinculados" (AMIGO, 2015, p. 52). Interpretado de esta manera, el Grupo constituye otra articulación de un colectivo de afrodescendientes, en este caso con el Estado y UNESCO, que confirma a los candombes como lenguaje de negociación política del colectivo, como lo fueron en el pasado.

Este aspecto también explica por qué se ha generalizado los candombes fuera de los barrios históricos. El nivel de apropiación de los sectores populares en los barrios de la periferia se explica entonces por distintos factores: porque es una forma de habitar los espacios públicos, porque crea instancias de sociabilidad y promueve el trabajo colectivo, y porque abre las puertas de una negociación con distintos actores locales. El cierre de la candidatura del candombe y de los "toques madre" en los tres barrios históricos implica conservar ciertas expresiones del candombe frente a su crecimiento incluso fuera de Montevideo, crea un espacio de privilegio para algunas comparsas y referentes, pero al mismo tiempo lleva adelante un plan para que los toques originales, que configuraban y configuran el ambiente sonoro de los barrios, puedan reproducirse, documentarse y difundirse. Si la comparsa, como espacio social, ofrece una herramienta de negociación política para actores de menor capital social y cultural que algunas comparsas de los barrios históricos, y contribuye a una mayor participación en la vida cultural de los sectores populares, es un aspecto a tener en cuenta a la hora de analizar la "apropiación" del candombe por parte de la sociedad envolvente, y a diferenciar a los sujetos populares de la mercantilización que proponen el Carnaval, la televisión o la industria de la música popular uruguaya. 


\section{CONCLUSIONES}

Si bien distintos actores mantienen las críticas al Desfile Oficial de Llamadas, una buena parte de las comparsas de Montevideo y el interior participan de la competencia, lo que continúa dotando al Barrio Sur de un sentido que trasciende sus fronteras territoriales, como lugar de memoria. Al mismo tiempo, también en los barrios Sur y Palermo, distintos actores están confluyendo para sostener esa memoria y organizan eventos que operan en ese sentido, como las llamadas de San Baltasar (el candombe de Reyes, los 6 de enero desde 2003) o las llamadas que se realizan el 3 de diciembre desde 2006, en conmemoración del "Día del Candombe, la cultura afrouruguaya y la equidad racial", organizadas por la Casa de la Cultura Afrouruguaya y AUDECA. ${ }^{4}$ Ambas acciones vuelven a poner el foco en las llamadas espontáneas anteriores al desfile oficial, tratando de eliminar algunos elementos de la organización desde arriba: no se compite y no se ponen límites al público (vallas) para su participación y no se apura a las comparsas para terminar. El recorrido que se eligió es un intermedio entre el de 1956 y el oficial actual, comienza en Cuareim y Carlos Gardel (continuación de Isla de Flores) hasta Isla de Flores y Ansina, el cierre se da en Ansina, entre Isla de Flores y San Salvador, calle emblemática del barrio, "tierra sagrada" como la denominó Chabela Ramírez un 3 de diciembre de 2016, arriba del escenario instalado en la puerta de la Casa de la Cultura Afrouruguaya.

La Casa se ha convertido desde su formulación como proyecto en 2007 y la inauguración de su local en 2011, en un espacio de referencia para este proceso de resistencia y construcción de sentido en los barrios históricos. En las llamadas del 3 de diciembre de 2018 participaron 38 comparsas de las cuales apenas 5 pertenecían a los barrios Sur y Palermo, lo que indica la voluntad de seguir ocupando ese lugar de memoria, al mismo tiempo convocando a las comparsas de todos los barrios, y resistiendo los planes oficiales y privados para el centro de la ciudad. También Organizaciones Mundo Afro, que en 1998 inicia las negociaciones con el Ministerio de Vivienda, Ordenamiento Territorial y Medio Ambiente (MVOTMA) para la creación de 40 viviendas en el Barrio Sur para mujeres solteras negras con hijos a cargo (FERREIRA, 2003, p. 48). El Programa se denomina Unidades Familiares Mundo Afro (UFAMA) y ha dado sus frutos recientemente. Según la página web oficial de Mundo Afro, entre 2005 y 2007 se concretaron dos proyectos UFAMA Palermo y UFAMA Cordón. En 2009 y 2011, informan, se firmaron convenios para la creación de más soluciones habitaciones para la población afodescendiente, al menos una en los barrios históricos, en los que la Intendencia cede terrenos para la construcción y la Dirección Nacional de Viviendas colabora en la construcción.

Todas estas acciones: la reparación simbólica de las familias desalojadas en la dictadura,

\footnotetext{
${ }^{4}$ Es interesante señalar que DAECPU realiza su propio desfile del 3 de diciembre que se hace lejos de los barrios históricos, en el que participan menos comparsas, y se entregan premios. En 2019 los eventos se realizaron el 30 de noviembre (DAECPU) y el 8 de diciembre (Casa de la Cultura Afrouruguaya y AUDECA), participaron 13 comparsas en el primero y 26 en el segundo, y solo se repiten 3 comparsas en ambos.
} 
a través del realojo en los barrios históricos, la salvaguarda de los toques madre y las llamadas fuera del concurso oficial, están operando para revertir los procesos de desterritorialización y pujando para que, en la apertura de los candombes a la cultura envolvente, no se desdibuje o se distorsione su origen africano y sobre todo su relación indisoluble con un territorio, una expresión artística, unas memorias de lucha contra el racismo y una comunidad barrial. Lo que marca la contemporaneidad de los candombes es, por un lado, la creciente identificación de la versión carnavalesca de la comparsa montevideana (vedette, personajes históricos, tambores) con el Uruguay como país; y por el otro, un trabajo de registro, difusión e investigación patrimonial de los candombes en sus barrios históricos, con su correspondiente legitimación oficial. Estos dos aspectos se articulan y se tensionan, y están relacionados también con una gran ampliación del candombe como expresión social y musical incluso fuera de Montevideo y del país, en la que tuvieron mucho que ver los medios de comunicación y la industria de la música popular uruguaya en la posdictadura.

En esas tensiones los distintos colectivos de afrodescendientes (organizaciones civiles y comparsas) han ocupado tanto posiciones de articulación con el Poder Ejecutivo, como responsabilidades en el Poder Legislativo y en el Ejecutivo. En el caso del candombe la creación del Grupo Asesor de Candombe en la Comisión de Patrimonio de la Nación (del MEC), es culminación de un proceso largo que comenzó en 2006 con la creación del "Día del candombe”, y que implicó una articulación política para la la formulación de leyes, la ratificación de Convenciones internacionales (Patrimonio Inmaterial y Diversidad Cultural) y la candidatura a la Lista Representativa de la UNESCO en 2009. El dispositivo del Patrimonio Inmaterial (BORTOLOTTO, 2014, p. 4) creado por la UNESCO y articulado con el Estado, brindó herramientas y aportó un lenguaje para las demandas históricas del colectivo, que reaccionan ante lo que sienten como una amenaza: la generalización del candombe en todo el país. Sin embargo, es necesario tomar en cuenta que en ese proceso de generalización del candombe no solamente se beneficiaron las industrias culturales sino un grupo grande de colectivos de los sectores populares que encuentran en la comparsa de candombe un lenguaje para apropiarse del barrio, expresarse artísticamente y realizar sus demandas.

Este trabajo exploratorio define una serie de articulaciones a profundizar en futuras investigaciones: las relaciones del candombe con la industria cultural (carnaval, canción), y su impacto en la masificación del candombe; las relaciones con el Estado, en los diferentes niveles de gobierno, y con los organismos internacionales; el lenguaje en el que se apoyan los procesos de patrimonialización y que se generalizan entre los actores: identidad, tradición, transmisión; y, finalmente, la forma que adquieren todas estas articulaciones en las comparsas barriales fuera de los barrios históricos, que requieren un trabajo de campo específico. El eje es una definición de los candombes como espacio y discurso de negociación del colectivo afrodescendiente con la sociedad envolvente, y su importante contribución a la creación de una esfera pública popular. 


\section{REFERENCIAS}

AHARONIÁN, Coriún. Músicas populares del Uruguay. Montevideo: Tacuabé, 2010 [2007].

ALFARO, Milita y José COZZO. Medio mundo. Sur, conventillo y después. Montevideo: Medio \& Medio, 2008.

ALTAMIRANDA BARBOZA, J. Afrodescendientes y política en Uruguay. Monografía (Graduación en Ciencia Política). Universidad de la Republica (Uruguay). Facultad de Ciencias Sociales, Montevideo. 2004.

AMIGO DÜRRE, Ricardo. El candombe como artefacto patrimonial. Trama. Revista de la Asociación Uruguaya de Antropología Social, n. 6, p. 46-56, 2015.

ANDREWS, Reid. Negros en la Nación Blanca: Historia de los Afro-Uruguayos 1830-2010. Montevideo: Linardi y Risso, 2011.

ARGAÑARAZ, N. N. "Cartografía del racismo. Un boceto preliminar". Revista Encuentros, n. 6, p. 9-19, 1999.

AYESTARÁN, Lauro. La música en el Uruguay. Vol. 1. Montevideo: SODRE, 1953.

-. El tamboril y la comparsa. Montevideo: Arca, 1990 [1965].

BENTON, Lauren A. La demolición de los conventillos: Ia política de vivienda en el Uruguay autoritario. Montevideo: CIESU/Banda Oriental, 1986.

BORTOLOTTO, Chiara. "La problemática del patrimonio cultural inmaterial". Culturas. Revista de gestión cultural, v. 1, n. 1, p. 1-22, 2014.

CABELLA, Wanda, Mathías NATHAN y Mariana TENENBAUM. Atlas sociodemográfico y de la desigualdad del Uruguay. Fascículo 2: La población afro-uruguaya en el Censo 2011. Montevideo: Trilce, 2013.

CARDOSO, Jorge Emilio. El desalojo en la calle de los negros. Afro-Hispanic Review, v. 15, n. 2, p. 3754, 1996.

FERREIRA, Luis. El movimiento negro en Uruguay (1988-1998). Montevideo: Etnicas/Mundo Afro, 2003.

-. Dimensiones afrocéntricas en la cultura performática uruguaya. In: GOLDMAN, Gustavo. Cultura y sociedad afro-rioplatense. Montevideo: Perro Andaluz, 2008, p. 91-123.

GARCÍA CANCLINI, Néstor. La sociedad sin relato. Antropología y estética de la inminencia. Colonia Suiza: Katz, 2010.

GRIMSON, Alejandro. Los límites de la cultura. Crítica de las teorías de la identidad. Buenos Aires: Siglo XXI, 2011.

HARVEY, David. El enigma del capital y la crisis del capitalismo. Madrid: Akal, 2013. 
MAGNONE, Valentín. "Dinámicas étnico-raciales en el espacio urbano de Montevideo". Trabajo presentado en las XVI Jornadas de Investigación de la Facultad de Ciencias Sociales, diciembre de 2017. (Disponible en: http://jornadas.cienciassociales.edu.uy/wp-content/ uploads/2017/10/Din\%C3\%A1micas-\%C3\%A9tnico-raciales-en-el-espacio-urbano-de-Montevideo Valent\%C3\%ADn-Magnonge.pdf).

MARGULIS, Mario. La "racialización" de las relaciones de clase. In: MARGULIS, Mario y URRESTI, Marcelo. La segregación negada. Cultura y discriminación social. Buenos Aires: Byblos, 1999, p. 37-62.

MERINO, Francisco M. El negro en la sociedad montevideana. Montevideo: Banda Oriental, 1982.

NASER, Lucía. "Una charla sobre carnaval, cultura y política con Chabela Ramírez". La diaria, 3 de febrero de 2017. En: https://ladiaria.com.uy/articulo/2017/2/una-charla-sobre-carnaval-cultura-ypolitica-con-chabela-ramirez/

OLIVERA CHIRIMINI, Tomás y VARESE, Juan Antonio. Los candombes de Reyes. Las llamadas. 2a. ed., Montevideo: El Galeón/Del Sur, 2009.

PORZECANSKI, Teresa y Beatriz SANTOS. Historias de exclusión: afrodescendientes en el Uruguay. Montevideo: Linardi y Risso, 2006 [1994].

RUIZ, Viviana y Valentina BRENA, Daniel «Tatita» MÁRQUEZ y Olga PICÚN. Patrimonio vivo del Uruguay: Relevamiento de Candombe. Montevideo: UNESCO-MEC, 2015.

SAMUELLE, Juan. "Peligra la participación de la mayoría de las comparsas en las Llamadas". El Observador. 27 de enero de 2017. En: https://www.elobservador.com.uy/nota/peligra-laparticipacion-de-la-mavoria-de-las-comparsas-en-las-llamadas-2017127500

SEGATO, Rita Laura. La nación y sus otros. Raza, etnicidad y diversidad religiosa en tiempos de políticas de la identidad. Buenos Aires: Prometeo, 2007.

TRIGO, Abril. "Candombe and the Reterritorialization of Culture". Callaloo, v. 16, n. 3, p. 716-728, 1993.

UNESCO. The Candombe and its socio-cultural space: a community practice. Expediente de la candidatura. Abu Dhabi, 2009. In: https://ich.unesco.org/es/RL/el-candombe-y-su-espaciosociocultural-una-practica-comunitaria-00182 